\title{
A Comparative Study of Ground and Underground Vibrations Induced by Bench Blasting
}

\author{
Xiuzhi Shi, Xianyang Qiu, Jian Zhou, Dan Huang, Xin Chen, and Yonggang Gou \\ School of Resources and Safety Engineering, Central South University, Changsha 410083, China \\ Correspondence should be addressed to Xianyang Qiu; qiuxianyang_csu@163.com
}

Received 19 June 2016; Accepted 19 September 2016

Academic Editor: Ivo Caliò

Copyright ( 2016 Xiuzhi Shi et al. This is an open access article distributed under the Creative Commons Attribution License, which permits unrestricted use, distribution, and reproduction in any medium, provided the original work is properly cited.

\begin{abstract}
Ground vibrations originating from bench blasting may cause damage to slopes, structures, and underground workings in close proximity to an operating open-pit mine. It is important to monitor and predict ground vibration levels induced by blasting and to take measures to reduce their hazardous effects. The aims of this paper are to determine the weaker protection objects by comparatively studying bench blasting induced vibrations obtained at surface and in an underground tunnel in an open-pit mine and thus to seek vibration control methods to protect engineering objects at the site. Vibrations arising from measurement devices at surface and in an underground tunnel at the Zijinshan Open-Pit Mine were obtained. Comparative analysis of the peak particle velocities shows that, in the greatest majority of cases, surface values are higher than underground values for the same vibration distance. The transmission laws of surface and underground vibrations were established depending on the type of rock mass, the explosive charge, and the distance. Compared with the Chinese Safety Regulations for Blasting (GB6722-2014), the bench blasting induced vibrations would not currently cause damage to the underground tunnel. According to the maximum allowable peak particle velocities for different objects, the permitted maximum charges per delay are obtained to reduce damage to these objects at different distances.
\end{abstract}

\section{Introduction}

Adverse effects of blasting are one of the fundamental problems in open-pit mines. Generally, only part of the energy released during blasting is utilized directly for breaking rock within a target range, whereas the remainder of the energy is passed to the surrounding rock, structures, and environment in the forms of ground vibration, noise, flying rocks, back break, and air blasts [1-3]. Ground vibration originating from blasting operations, which can cause damage to nearby building structures and residences, is considered as the main blasting hazard [4-7]. Therefore, it is important to monitor, predict, and control ground vibration arising from blasting.

Over the years, many research studies have investigated vibrations induced by blasting in open-pit mines. For instance, Shi and Chen [8] successfully reduced the vibration intensity by controlling maximum charge amount per delay and selecting optimum interval time in an open-pit mine. Simangunsong and Wahyudi [9] and Görgülü et al. [10] studied the ground vibrations induced by open-pit blasting using an artificial neural network. With the increase of openpit and underground combined mining and the occasional need of open-pit mining, several underground workings may be located in close proximity to an operating open-pit mine. In these cases, ground vibrations generated due to openpit blasting may be hazardous to the stability of adjoining underground workings as well as surface building structures and residences [11-13]. Different rock mass characteristics at surface and in underground levels cause underground vibration damping [14].

Determination of weaker protection objects at surface and in underground tunnel is of great importance to control vibrations induced by bench blasting. In this study, blast induced ground vibrations obtained at surface and in an underground transport tunnel are comparatively examined and used to determine which are the weaker protection objects that may be damaged by blasting induced vibration. Furthermore, the peak particle velocity (PPV) is estimated depending on the maximum charge amount per delay $(Q)$ and distance $(R)$. Finally, according to the Chinese Safety 


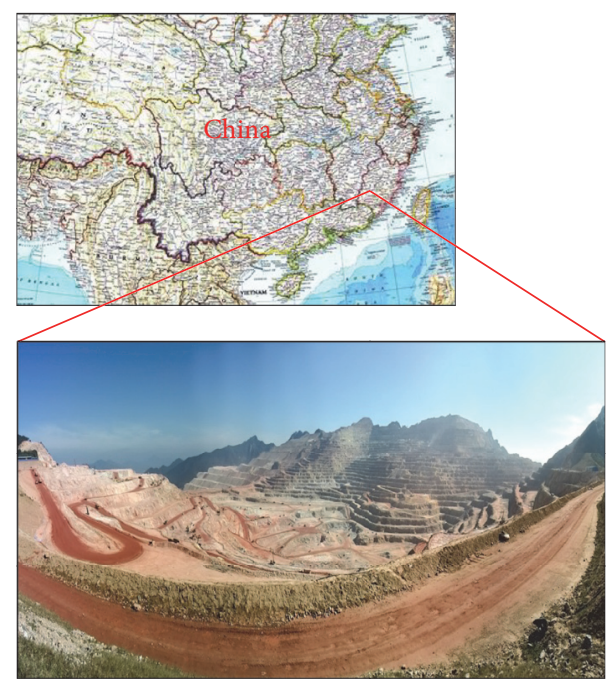

FIGURE 1: Location of the open-pit mine.

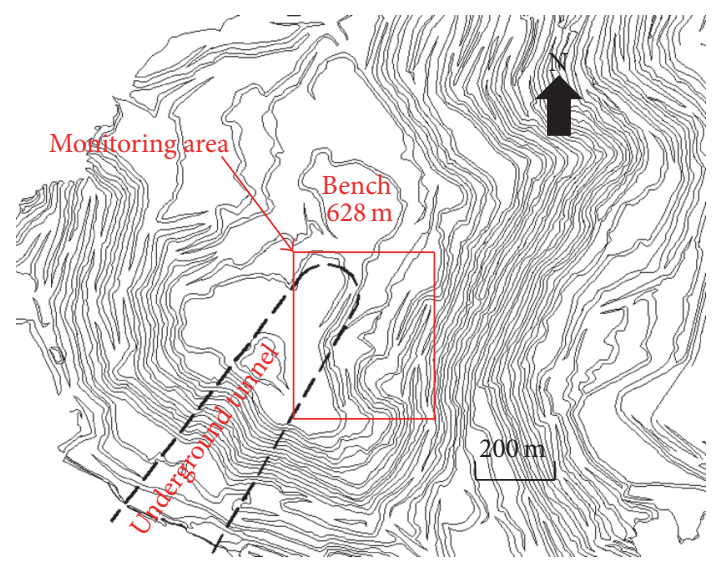

FIGURE 2: Transport tunnel position of the open-pit mine.

Regulations for Blasting [15], the maximum charge amount per delay is controlled for different protection objects.

\section{Description of the Study Area}

This study was conducted at the Zijinshan Open-Pit Mine, which is located in Shanghang County, Fujian Province, China. The satellite image of the mine taken from Google Earth is shown in Figure 1. South of the open-pit mine is a village called Chatouping. The distance from the closest building of the village to the open-pit mine is approximately $500 \mathrm{~m}$.

Figure 2 shows the position of the underground transport tunnel, in which the relative position of the underground tunnel and the open-pit mine can be observed. The elevation of the lowest bench is $592 \mathrm{~m}$, and the elevation of the transport tunnel is $517 \mathrm{~m}$.

The rock type of the mine consists of medium grained granite, cryptoexplosive breccia, and porphyritic dacite. The
TABLE 1: General applied design parameters at the mine.

\begin{tabular}{lc}
\hline Parameters & Value \\
\hline Slope, $\alpha\left(^{\circ}\right)$ & 75 \\
Diameter, $d(\mathrm{~mm})$ & 165 \\
Hole length, $H(\mathrm{~m})$ & $12 \sim 13.5$ \\
Bench height, $K(\mathrm{~m})$ & 12 \\
Burden, $B(\mathrm{~m})$ & 6 \\
Spacing, $S(\mathrm{~m})$ & 4 \\
Stemming, $h_{0}(\mathrm{~m})$ & 2 \\
Delay time & 25 ms (hole), $65 \mathrm{~ms}$ (row) \\
Maximum charge per delay, $Q(\mathrm{~kg})$ & $100 \sim 200$ \\
Explosive & ANFO \\
\hline
\end{tabular}

rock is mainly hard rock with some thin layers of local weak rock.

\section{Control Parameters and Measuring Equipment}

3.1. Blasting Parameters. The main blasting area was bench $628 \mathrm{~m}$. The design parameters generally applied for blasting operations at the mine are given in Table 1.

3.2. Blasting Vibration Monitoring. To comparatively study the underground and surface vibrations induced by the bench blasting, the vibrations generated by blasting in the mine were recorded both on the surface and underground. The underground and surface measurements were not gathered simultaneously. The underground measurements were collected from September 2013 to November 2013, whereas the surface measurements were collected from November 2013 to July 2014. The charge quantity per delay parameters and the distance between the blasts and the station were carefully recorded. The distances between the shot points and monitor stations were calculated using the coordinates of each location.

A seismic YBJ-1 type of velocity recording instrument supplied by Beijing Instrument Factory was adopted in this study. Blasts were mainly carried out on bench $628 \mathrm{~m}$. At surface, monitoring station points were placed on benches with different elevations in the south of the blasting site. Selected monitoring station points were convenient to the assembled instruments. To monitor the underground vibration induced by the bench blasting, monitoring station points were placed in the underground tunnel, almost the same plane position with the surface (Figure 2). The measurement devices were installed on the middle top of the tunnel by anchors built into the rock. The installation patterns on the bench and in the tunnel are shown in Figure 3. The main vibration measurement parameters were velocity and frequency. Only the vertical velocity measurements were collected in the tunnel, whereas the velocity of three directions was measured on the bench. A number of bench measurement results showed that the peak vertical particle velocities are the largest among the three vibration components of the monitoring 


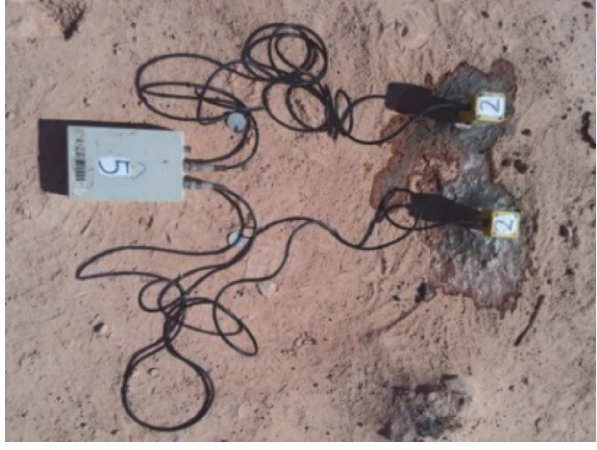

(a)

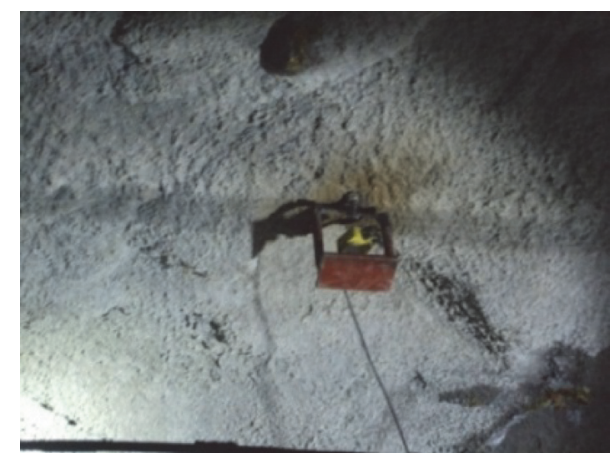

(b)

FiguRE 3: Installation patterns on the bench and in the tunnel. (a) Surface. (b) Underground.

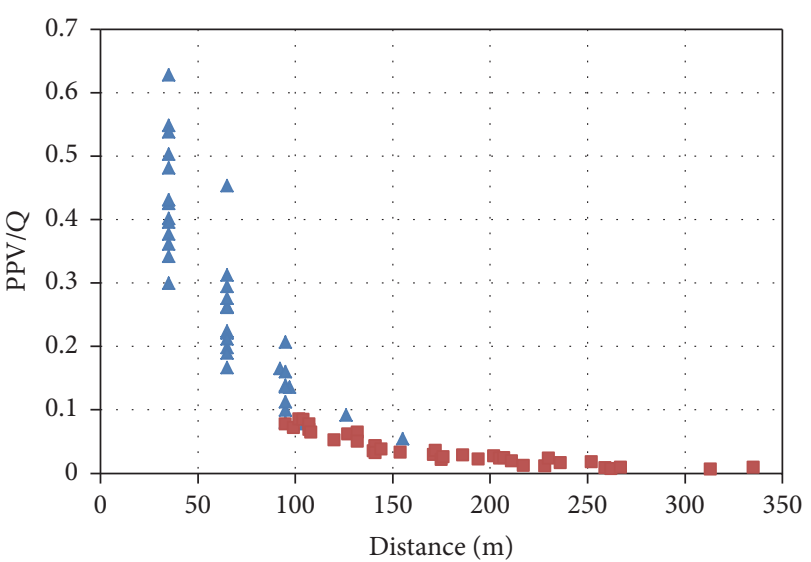

^Surface

- Underground

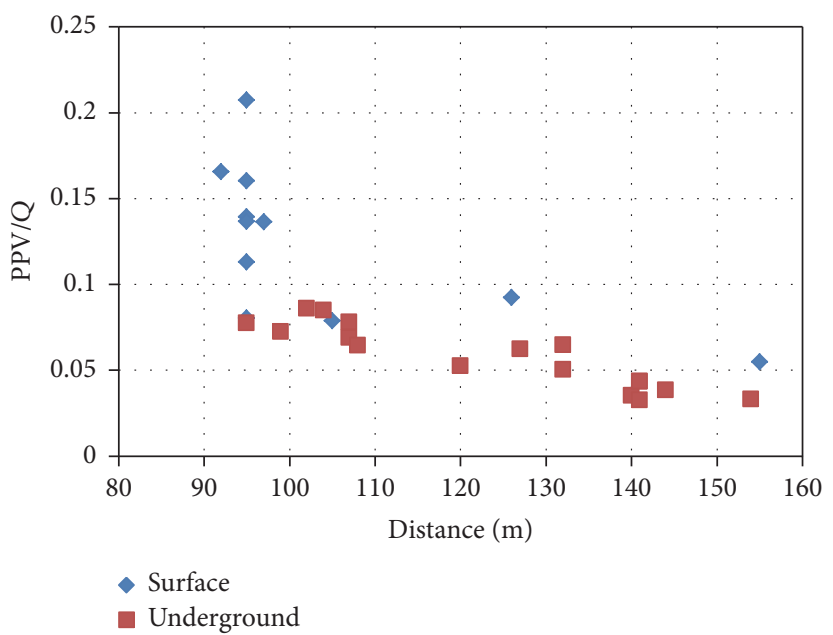

(b)

(a)

FIGURE 4: Representation of PPV per unit charge versus the distance on surface and underground. (a) Total figure. (b) Partial figure.

points. So, the peak vertical particle velocities of the surface vibration are used in this study.

In all, 37 recordings of underground vibrations were made from 17 blasts, and 37 recordings of surface vibrations were made from 16 blasts.

\section{Analysis of Ground and Underground Vibrations Induced by Bench Blasting}

4.1. Comparative Study of Surface and Underground Vibrations. To intuitively compare vibrations obtained from measurement devices at surface and in underground tunnel, Figure 4 shows the values of PPV per unit charge by delay versus the distances between the blast and the monitor stations both on surface and in tunnel [14]. As shown in Figure 4, the distances from the monitoring stations on the surface to the blasts are universally below $150 \mathrm{~m}$, whereas those underground are above $90 \mathrm{~m}$. To rule out the influence of different distances, only vibrations for distances from 90 to $160 \mathrm{~m}$ are to be comparatively studied.

From the enlarged view in Figure 4, it can be clearly observed that, in the greatest majority of cases, the values obtained on the surface are higher than those from underground for the same distance. Although the underground and surface measurements were not taken simultaneously, the geological conditions of the mine, the blasting parameters, and other environmental factors that may influence the propagation of vibration waves were almost identical in the measuring period. Therefore, the data obtained from the surface and underground areas in the open-pit mine are evidence of the existence of vibration damping from surface to underground.

4.2. Determination of the Law of Transmission of Vibrations. To prevent and control the vibrations resulting from blasting, the laws of transmission of vibrations were established considering the type of rock mass, the explosive charge, and the distance using the data obtained on the surface and underground.

Peak particle velocity (PPV) is generally a direct function of the maximum charge per delay called " $Q$ " and is negatively related to the distance between the blasting point and the recording point [16]. To find a mathematical expression of the determination of the laws of transmission of vibrations, 
TABLE 2: Vibration measurements taken in tunnel.

\begin{tabular}{|c|c|c|c|c|c|}
\hline Blast & Bench & $Q$, maximum charge by delay $(\mathrm{kg})$ & $D$, distance $(\mathrm{m})$ & $\mathrm{PPV}(\mathrm{mm} / \mathrm{s})$ & Frequency $(\mathrm{Hz})$ \\
\hline 1 & 628 & 174 & 313 & 0.7 & 14.6 \\
\hline \multirow{3}{*}{2} & \multirow{3}{*}{628} & 175 & 102 & 15.1 & 31.1 \\
\hline & & 175 & 132 & 14.3 & 32.3 \\
\hline & & 175 & 172 & 6.3 & 32.3 \\
\hline \multirow{4}{*}{3} & \multirow{4}{*}{628} & 175 & 262 & 1.3 & 32.9 \\
\hline & & 175 & 217 & 2.1 & 33.9 \\
\hline & & 175 & 141 & 5.2 & 32.9 \\
\hline & & 175 & 120 & 3.1 & 32.3 \\
\hline \multirow{3}{*}{4} & \multirow{3}{*}{628} & 175 & 107 & 15.0 & 32.9 \\
\hline & & 175 & 144 & 4.7 & 32.9 \\
\hline & & 175 & 186 & 5.8 & 32.9 \\
\hline \multirow{3}{*}{5} & \multirow{3}{*}{628} & 175 & 335 & 2.3 & 31.7 \\
\hline & & 175 & 228 & 2.1 & 32.9 \\
\hline & & 175 & 207 & 6.3 & 32.9 \\
\hline 6 & 628 & 173 & 267 & 1.6 & 30.5 \\
\hline \multirow{3}{*}{7} & \multirow{3}{*}{628} & 175 & 205 & 6.2 & 16.5 \\
\hline & & 175 & 132 & 4.3 & 31.7 \\
\hline & & 175 & 141 & 7.6 & 33.6 \\
\hline \multirow{2}{*}{8} & \multirow{2}{*}{628} & 175 & 259 & 1.5 & 29.9 \\
\hline & & 175 & 211 & 5.4 & 33.6 \\
\hline \multirow{2}{*}{9} & \multirow{2}{*}{628} & 175 & 236 & 2.9 & 34.3 \\
\hline & & 175 & 154 & 3.9 & 35.4 \\
\hline 10 & 628 & 175 & 176 & 4.5 & 35.4 \\
\hline \multirow{2}{*}{11} & \multirow{2}{*}{616} & 175 & 140 & 5.1 & 35.4 \\
\hline & & 175 & 127 & 15.9 & 33.5 \\
\hline \multirow{2}{*}{12} & \multirow{2}{*}{628} & 175 & 175 & 3.8 & 35.4 \\
\hline & & 175 & 171 & 3.2 & 33.6 \\
\hline \multirow{2}{*}{13} & \multirow{2}{*}{628} & 173 & 104 & 3.9 & 62.0 \\
\hline & & 173 & 252 & 7.1 & 33.6 \\
\hline \multirow{3}{*}{14} & \multirow{3}{*}{616} & 174 & 141 & 5.7 & 32.3 \\
\hline & & 174 & 108 & 6.2 & 35.0 \\
\hline & & 174 & 95 & 13.5 & 33.6 \\
\hline 15 & 628 & 175 & 202 & 4.8 & 34.2 \\
\hline \multirow{3}{*}{16} & \multirow{3}{*}{628} & 173 & 230 & 5.5 & 61.0 \\
\hline & & 173 & 107 & 24.5 & 88.8 \\
\hline & & 173 & 99 & 12.5 & 95.2 \\
\hline 17 & 628 & 175 & 194 & 3.9 & 34.2 \\
\hline
\end{tabular}

the "scaled distance," which is defined as the relation between the distance and the energy of the explosive charge, was used [17]. The scaled distance was calculated as

$$
D_{\text {scaled }}=\frac{D}{\sqrt{Q}}
$$

where $D_{\text {scaled }}$ is the scaled distance, $D$ is the distance between the emitted point and received point in $m$, and $Q$ is the amount of maximum charge per delay in $\mathrm{kg}$.

The empirical relation between the PPV and the scaled distance is then obtained, which takes the following form:

$$
\mathrm{PPV}=K \times\left(D_{\text {scaled }}\right)^{\alpha} .
$$

The values obtained for PPV and $D_{\text {scaled }}$ are plotted to determine the value of the constants $K$ and $\alpha$, which will depend on geological conditions. Then, the equation of the regression curve that best fits the plot is obtained. The law of transmission of underground vibration was obtained using the data from Table 2. Figure 5 shows the pairs of values formed by the scaled distance and the PPV. Using the equation of the regression curve in Figure 5, the following transmission law for underground vibration is obtained:

$$
\mathrm{PPV}=86.28 \times\left(\frac{D}{\sqrt{Q}}\right)^{-2.02}
$$




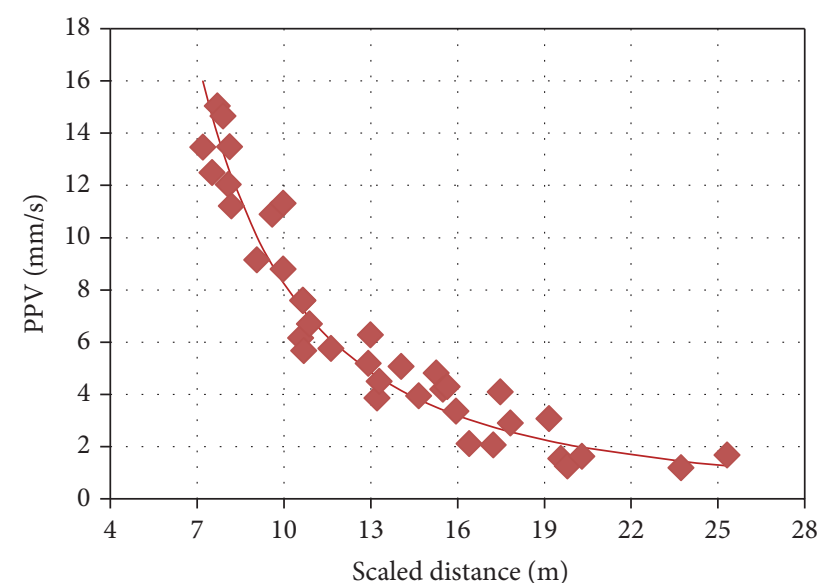

FIGURE 5: Relations between PPV and the scaled distance for underground vibrations.

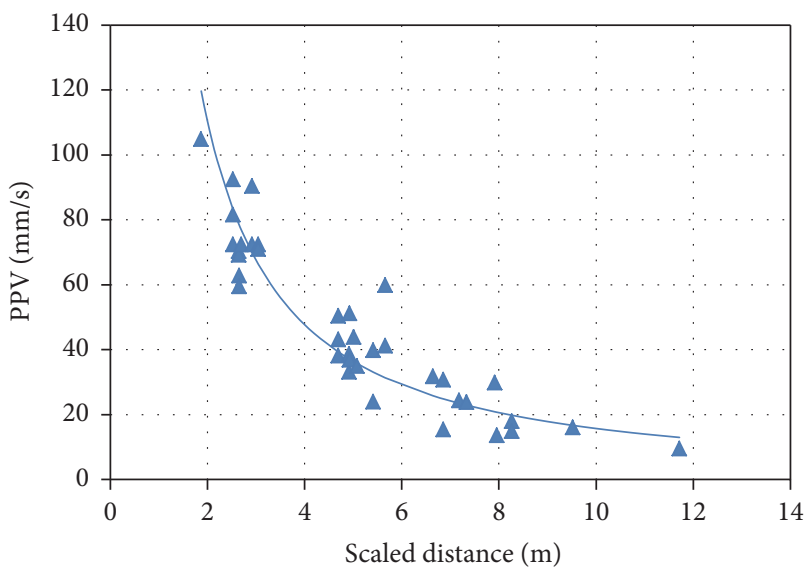

FIGURE 6: Relations between PPV and the scaled distance for surface vibrations.

The law of transmission of surface vibration was obtained using the data from Table 3. Figure 6 shows the pairs of values formed by the scaled distance and the PPV. Using the equation of the regression curve in Figure 6, the following transmission law for underground vibration is obtained:

$$
\mathrm{PPV}=25.54 \times\left(\frac{D}{\sqrt{\mathrm{Q}}}\right)^{-1.21} .
$$

The fitting coefficients for the transmission laws of the bench blasting induced vibrations measured on the surface and underground are 0.91 and 0.85 , respectively. So, the fitting degree for surface vibrations is higher than that for measurements taken underground because surface vibrations are greatly influenced by topographic changes at the surface level; as depth increases, the rock mass is increasingly homogeneous.

\section{Maximum Charge Control Based on the Transmission of Vibration}

5.1. Distribution of PPV with Frequency Compared with Regulations. Open-pit blasting induced vibrations might

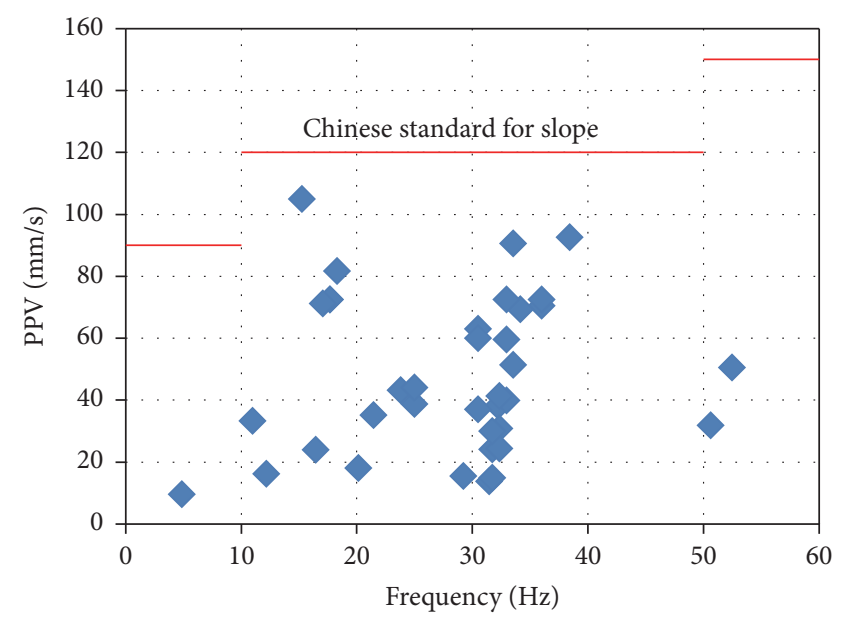

FIGURE 7: Representation of surface vibration in relation to Chinese standards.

affect the transport tunnel and constructional engineering components close to the open-pit mine, so the obtained vibrations are estimated and compared to the Chinese Safety Regulations for Blasting (GB6722-2014) released in 2014 [15].

The permitted peak particle velocities for different structures advised by GB6722-2014 are listed in Table 4. In the Zijinshan Mine, the structures influenced by the surface and underground vibrations are the permanent slope and the underground tunnel, respectively. The standard level for the roadway in the mine is suitable for an underground tunnel in the Zijinshan Mine. Figure 7 shows all pairs of vibration frequency-velocity values on the surface and the permitted peak particle velocities of different frequencies for a permanent slope. It can be observed that all surface recordings of the blasts are situated below the standard level of the permanent slope. However, some recordings are very close to the standard level, which means measures must be taken to reduce the surface vibrations. Figure 8 shows the situation of all pairs of underground vibration frequencyvelocity values and the permitted peak particle velocities of different frequencies for the mine roadway. It is clear that all underground recordings of the blasts are situated far below the standard level of the mine roadway. Therefore, the underground vibrations under current blasting design are unlikely to be hazardous to the underground tunnel. Under such conditions, the main objects forced by blasting vibration control are different architecture and structures on the surface.

5.2. PPV Estimation of Surface Vibration. Peak particle velocity of the bench blasting induced vibrations in the mine can be estimated according to the transmission law of vibrations. In Figure 9, the peak particle velocity of surface vibration can be estimated depending on the maximum charge amount per delay $(Q)$ and distance $(D)$. For structures of a certain distance from the blasting source, the extent of the blasting influence on them can be evaluated by comparing the assessed peak particle velocity to Chinese Safety Regulations for Blasting. For instance, for a $100 \mathrm{~kg}$ charge per delay, 
TABLE 3: Vibration measurements taken on surface.

\begin{tabular}{|c|c|c|c|c|c|}
\hline Blast & Bench & $Q$, maximum charge by delay $(\mathrm{kg})$ & $D$, distance $(\mathrm{m})$ & $\mathrm{PPV}(\mathrm{mm} / \mathrm{s})$ & Frequency $(\mathrm{Hz})$ \\
\hline \multirow{2}{*}{1} & \multirow{2}{*}{628} & 350 & 35 & 104.9 & 15.3 \\
\hline & & 350 & 95 & 5.1 & 21.5 \\
\hline \multirow{2}{*}{2} & \multirow{2}{*}{628} & 174 & 35 & 2.9 & 30.5 \\
\hline & & 174 & 65 & 51.3 & 33.5 \\
\hline \multirow{2}{*}{3} & \multirow{2}{*}{628} & 174 & 35 & 59.5 & 32.9 \\
\hline & & 174 & 65 & 36.9 & 30.5 \\
\hline \multirow{2}{*}{4} & \multirow{2}{*}{628} & 175 & 35 & 7.0 & 36.0 \\
\hline & & 175 & 65 & 38.7 & 25.0 \\
\hline 5 & 628 & 174 & 105 & 13.7 & 31.5 \\
\hline \multirow{2}{*}{6} & \multirow{2}{*}{628} & 175 & 35 & 69.3 & 34.2 \\
\hline & & 175 & 95 & 64.3 & 32.3 \\
\hline \multirow{2}{*}{7} & \multirow{2}{*}{628} & 175 & 65 & 3.2 & 11.7 \\
\hline & & 175 & 155 & 5.6 & 4.9 \\
\hline \multirow{2}{*}{8} & \multirow{2}{*}{628} & 175 & 97 & 23.8 & 16.5 \\
\hline & & 175 & 126 & 3.1 & 12.2 \\
\hline \multirow{2}{*}{9} & \multirow{2}{*}{628} & 144 & 35 & 72.4 & 32.9 \\
\hline & & 144 & 65 & 4.0 & 31.7 \\
\hline \multirow{3}{*}{10} & \multirow{3}{*}{628} & 132 & 35 & 72.4 & 17.7 \\
\hline & & 132 & 65 & 71.3 & 32.3 \\
\hline & & 132 & 95 & 68.0 & 20.1 \\
\hline \multirow{3}{*}{11} & \multirow{3}{*}{628} & 192 & 35 & 72.4 & 17.7 \\
\hline & & 192 & 65 & 43.1 & 23.8 \\
\hline & & 192 & 95 & 30.7 & 32.3 \\
\hline \multirow{3}{*}{12} & \multirow{3}{*}{628} & 132 & 35 & 71.1 & 17.1 \\
\hline & & 132 & 65 & 59.9 & 30.5 \\
\hline & & 132 & 95 & 4.9 & 31.7 \\
\hline \multirow{3}{*}{13} & \multirow{3}{*}{628} & 144 & 35 & 90.5 & 33.6 \\
\hline & & 144 & 65 & 39.8 & 32.9 \\
\hline & & 144 & 95 & 29.9 & 31.7 \\
\hline \multirow{3}{*}{14} & \multirow{3}{*}{628} & 192 & 35 & 92.5 & 38.4 \\
\hline & & 192 & 65 & 38.1 & 32.2 \\
\hline & & 192 & 95 & 5.4 & 29.2 \\
\hline \multirow{3}{*}{15} & & 192 & 35 & 21.7 & 18.3 \\
\hline & 628 & 192 & 65 & 70.5 & 52.5 \\
\hline & & 192 & 92 & 71.8 & 50.7 \\
\hline 16 & 628 & 168 & 35 & 72.4 & 36.0 \\
\hline & & 168 & 65 & 43.9 & 25.0 \\
\hline
\end{tabular}

TABLE 4: Blasting induced vibration permitted according to Chinese standards.

\begin{tabular}{lccc}
\hline \multirow{2}{*}{ Protective object } & \multicolumn{3}{c}{ Permitted PPV $(\mathrm{mm} / \mathrm{s})$} \\
& $<10 \mathrm{~Hz}$ & $10-50 \mathrm{~Hz}$ & $>50 \mathrm{~Hz}$ \\
\hline House built of soil or stone & $1.5-4.5$ & $4.5-9$ & $9-15$ \\
General civil building & $15-20$ & $20-25$ & $25-30$ \\
Industrial building & $25-35$ & $35-45$ & $42-50$ \\
Ancient relic & $1-2$ & $2-3$ & $3-5$ \\
Permanent slope & $50-90$ & $80-120$ & $100-150$ \\
Roadway in mine & $150-180$ & $180-250$ & $200-300$ \\
\hline
\end{tabular}

the peak particle velocity at a distance of $50 \mathrm{~m}$ is estimated to be $36.4 \mathrm{~mm} / \mathrm{s}$; for $200 \mathrm{~kg}$ charge per delay, the peak particle velocity at a distance of $200 \mathrm{~m}$ is estimated to be $10.3 \mathrm{~mm} / \mathrm{s}$.

5.3. Maximum Charge Control for Different Protection Objects. According to Chinese Safety Regulations for Blasting in Table 4, the frequencies of recorded surface signals can be classified, thus to determine the maximum allowable peak particle velocities for different protection objects.

The frequencies of recorded peak particle velocities of surface vibration are shown in Figure 10. In all 37 recorded signals, the number of the recorded signals with frequencies less than $10 \mathrm{~Hz}$ is 1 and the ratio is $3 \%$. The number of the recorded signals with frequencies between 10 and $50 \mathrm{~Hz}$ is 34 and the ratio detonates to $92 \%$. For recorded signals 


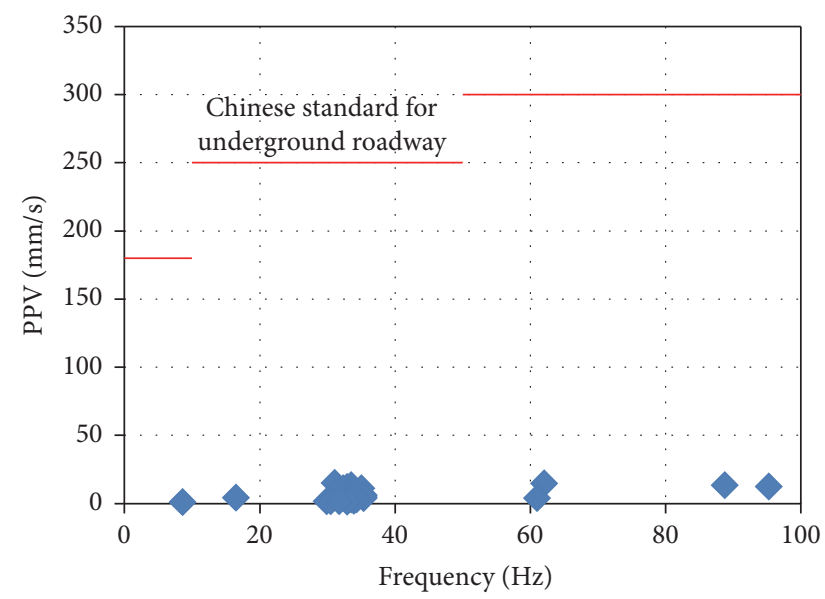

FIGURE 8: Representation of underground vibration in relation to Chinese standards.

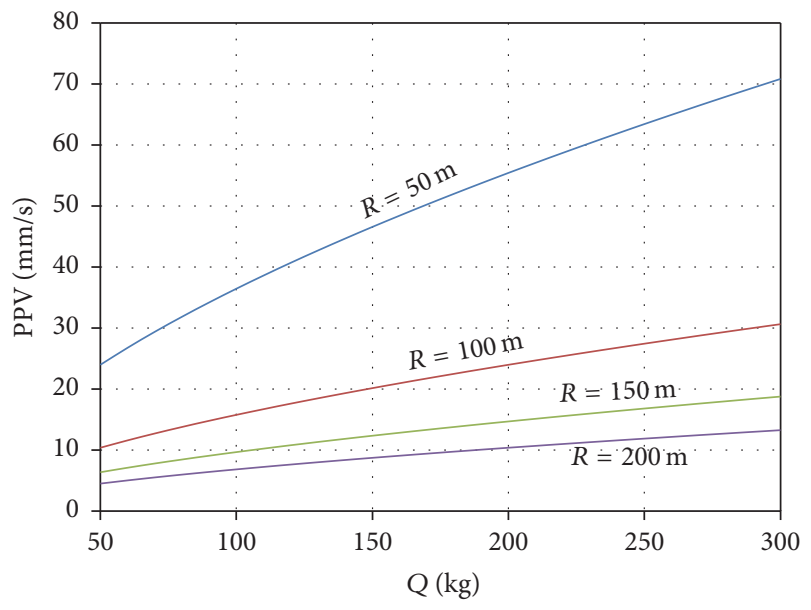

Figure 9: Surface PPV dependent on $Q$ and $D$.

with frequencies more than $50 \mathrm{~Hz}$, the number is 2 and the ratio is $5 \%$. Therefore, the open-pit mine can be classified as a low frequency site where the detonating frequencies are between 10 and $50 \mathrm{~Hz}$. According to Chinese Safety Regulations for Blasting in Table 4, the maximum allowable peak particle velocities for different protection objects are obtained. For example, the maximum allowable peak particle velocity for permanent slope in the site is $150 \mathrm{~mm} / \mathrm{s}$, whereas for industrial buildings the velocity is $45 \mathrm{~mm} / \mathrm{s}$.

Generally, many factors including the blasting source and transmission route influence the blasting vibration effect in an open-pit mine [18]. The transmission route factors are commonly unmanageable, such as distance from blasting, elevation differences, and geological conditions. Adjusting the variable blasting source factors usually reduces the intensity of blasting induced vibration. The blasting source factors include total charge, maximum charge per delay, delay time, direction of the burden, and charge structure. Among all blasting source factors, maximum charge per delay is the most easily controlled factor, which is directly related to the amplitude of blasting vibration [19]. So, control of the

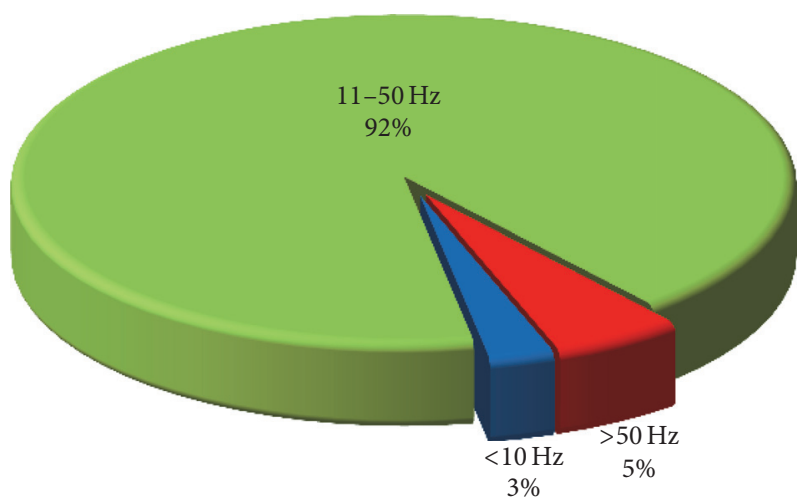

FIGURE 10: Vibration frequency of recorded events.

maximum charge per delay is studied to mitigate the possible damage to protection objects. The attenuation formula of surface vibration (see (4)) can be changed to the following formula:

$$
Q=\left(\frac{\mathrm{PPV} \times R^{1.21}}{25.54}\right)^{1.65}
$$

The maximum allowable peak particle velocity of different objects is brought into (5), and the permitted maximum charges per delay at different distances are obtained. In Figure 11, to protect the permanent slope at a distance of $40 \mathrm{~m}$, the limited maximum charge per delay is $459.3 \mathrm{~kg}$; for a house built of soil or stone at a distance of $200 \mathrm{~m}$, the maximum charge per delay should not exceed $158.7 \mathrm{~kg}$.

\section{Conclusions}

Vibrations obtained from measurement devices at surface and in underground tunnel are studied. The comparative analysis of the peak particle velocities shows that, in the greatest majority of cases, the values obtained at surface are higher than the values obtained in underground tunnel at the same distance, which proves the existence of vibration damping from the surface to underground.

The transmission laws of vibrations obtained on the surface and underground were established depending on the type of rock mass, the explosive charge, and the distance. The different fitting degrees for surface and underground vibrations indicate the influence of topographic changes and rock properties on the propagation of blasting induced vibration.

The obtained vibrations are estimated and compared to the Chinese Safety Regulations for Blasting (GB6722-2014). It is shown that the underground vibrations under current blasting design are unlikely to be hazardous for underground mine tunnels.

Peak particle velocity for the bench blasting induced surface vibrations in the mine can be estimated depending on maximum charge per delay $(Q)$ and distance $(D)$. Control of the maximum charge per delay is used to mitigate the possible damage to protection objects. Permitted maximum charges 


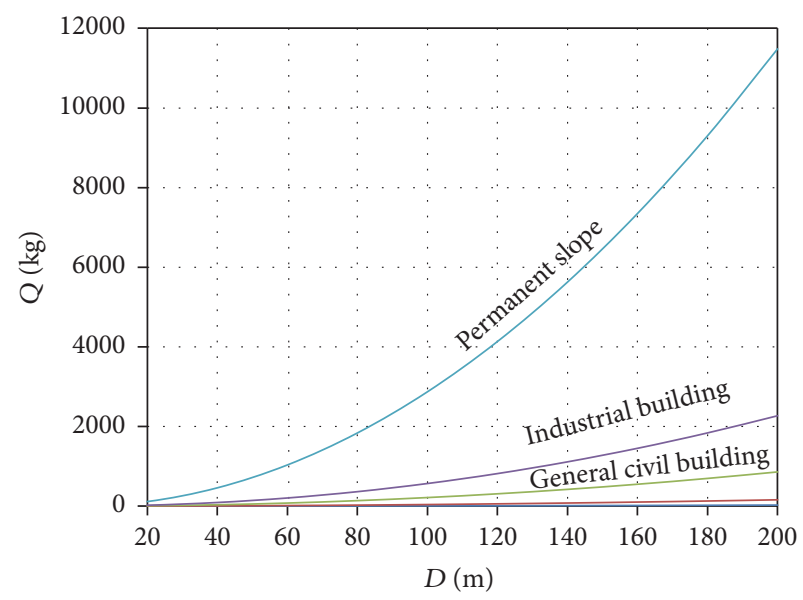

(a)

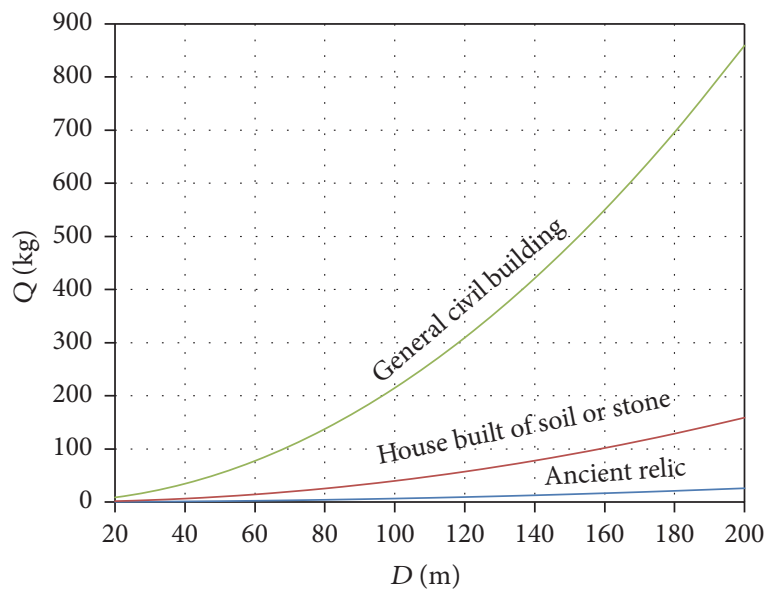

(b)

Figure 11: Control of maximum charge per delay for different protection objects dependent on $D$. (a) Total figure. (b) Partial figure.

per delay are obtained to protect objects at different distances according to the maximum allowable peak particle velocity.

\section{Competing Interests}

The authors declare that they have no competing interests.

\section{Acknowledgments}

This work was supported by the National 12th FiveYear Science and Technology Supporting Plan of China (2013BAB02B05) and supported by the Fundamental Research Funds for the Central Universities of Central South University (2016zzts094). The authors are grateful to the School of Resources and Safety Engineering of Center South University and Zijin Mining Group Co. Ltd. for their support. The authors are also very grateful to the staff of Zijinshan Gold-Copper Mine for their hospitality and invaluable support during the field investigation.

\section{References}

[1] C.-P. Lu, L.-M. Dou, X.-R. Wu, and Y.-S. Xie, "Case study of blast-induced shock wave propagation in coal and rock," International Journal of Rock Mechanics and Mining Sciences, vol. 47, no. 6, pp. 1046-1054, 2010.

[2] M. Monjezi, M. Ghafurikalajahi, and A. Bahrami, "Prediction of blast-induced ground vibration using artificial neural networks," Tunnelling and Underground Space Technology, vol. 26, no. 1, pp. 46-50, 2011.

[3] Z. Wang, X. Liang, Y. Chen, F. Li, and G. Liu, "Study of safety evaluation method of blasting vibration based on input energy," Chinese Journal of Rock Mechanics and Engineering, vol. 29, no. 12, pp. 2492-2499, 2010 (Chinese).

[4] R. Nateghi, "Evaluation of blast induced ground vibration for minimizing negative effects on surrounding structures," Soil Dynamics and Earthquake Engineering, vol. 43, pp. 133-138, 2012.
[5] C. Kuzu and E. Guclu, "The problem of human response to blast induced vibrations in tunnel construction and mitigation of vibration effects using cautious blasting in half-face blasting rounds," Tunnelling and Underground Space Technology, vol. 24, no. 1, pp. 53-61, 2009.

[6] H. Ak, M. Iphar, M. Yavuz, and A. Konuk, "Evaluation of ground vibration effect of blasting operations in a magnesite mine," Soil Dynamics and Earthquake Engineering, vol. 29, no. 4, pp. 669676, 2009.

[7] J. Zhou, X. Z. Shi, and X. B. Li, "Utilizing gradient boosted machine for the prediction of damage to residential structures owing to blasting vibrations of open pit mining," Journal of Vibration and Control, vol. 22, no. 19, pp. 3986-3997, 2016.

[8] X. Z. Shi and SH. R. Chen, "Delay time optimization in blasting operations for mitigating the vibration-effects on final pit walls' stability," Soil Dynamics and Earthquake Engineering, vol. 31, no. 8, pp. 1154-1158, 2011.

[9] G. M. Simangunsong and S. Wahyudi, "Effect of bedding plane on prediction blast-induced ground vibration in open pit coal mines," International Journal of Rock Mechanics and Mining Sciences, vol. 79, pp. 1-8, 2015.

[10] K. Görgülü, E. Arpaz, A. Demirci, A. Koçaslan, M. K. Dilmaç, and A. Gürkan Yüksek, "Investigation of blast-induced ground vibrations in the Tülü boron open pit mine," Bulletin of Engineering Geology and the Environment, vol. 72, no. 3, pp. 555564, 2013.

[11] P. K. Singh, M. P. Roy, R. K. Paswan, R. K. Dubey, and C. Drebenstedt, "Blast vibration effects in an underground mine caused by open-pit mining," International Journal of Rock Mechanics and Mining Sciences, vol. 80, pp. 79-88, 2015.

[12] P. K. Singh, "Blast vibration damage to underground coal mines from adjacent open-pit blasting," International Journal of Rock Mechanics and Mining Sciences, vol. 39, no. 8, pp. 959-973, 2002.

[13] P. K. Singh and M. P. Roy, "Damage to surface structures due to blast vibration," International Journal of Rock Mechanics and Mining Sciences, vol. 47, no. 6, pp. 949-961, 2010.

[14] C. González-Nicieza, M. I. Álvarez-Fernandez, A. E. AlvarezVigil, D. Arias-Prieto, F. López-Gayarre, and F. L. RamosLopez, "Influence of depth and geological structure on the transmission of blast vibrations," Bulletin of Engineering Geology and the Environment, vol. 73, no. 4, pp. 1211-1223, 2014. 
[15] AQSIQ and SAC, "Safety regulations for blasting," Chinese Standard GB6722-2014, China Water Power Press, Beijing, China, 2014 (Chinese).

[16] M. Khandelwal and T. N. Singh, "Evaluation of blast-induced ground vibration predictors," Soil Dynamics and Earthquake Engineering, vol. 27, no. 2, pp. 116-125, 2007.

[17] W. U. Zhen-zhi, H. U. Guo-xiang, and Z.-W. Deng, "Discussion on the safety criteria for blasting vibration," Safety and Environmental Engineering, vol. 10, no. 4, pp. 64-66, 2003 (Chinese).

[18] C. Huang, J. Chen, X. Luo, and Z. Rong, "Grey relational analysis on influence factors of blasting vibration in open-pit slope," Blasting, vol. 27, no. 2, pp. 96-98, 2010 (Chinese).

[19] X. Shi, Study of Time and Frequency Analysis of Blasting Vibration Signal and the Prediction of Blasting Vibration Characteristic Parameters and Damage, Central South University, Changsha, China, 2007 (Chinese). 


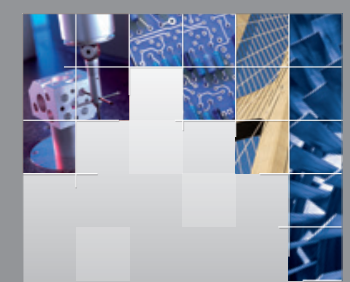

\section{Enfincering}
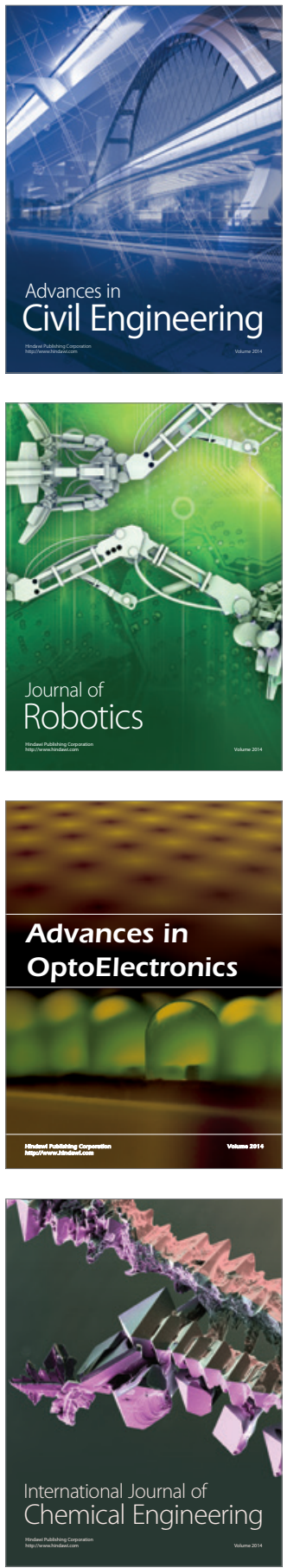

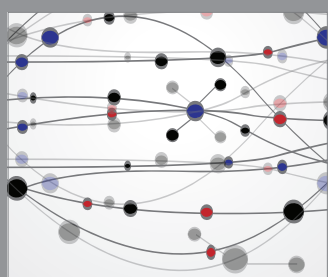

The Scientific World Journal

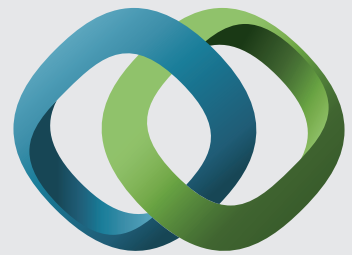

\section{Hindawi}

Submit your manuscripts at

http://www.hindawi.com
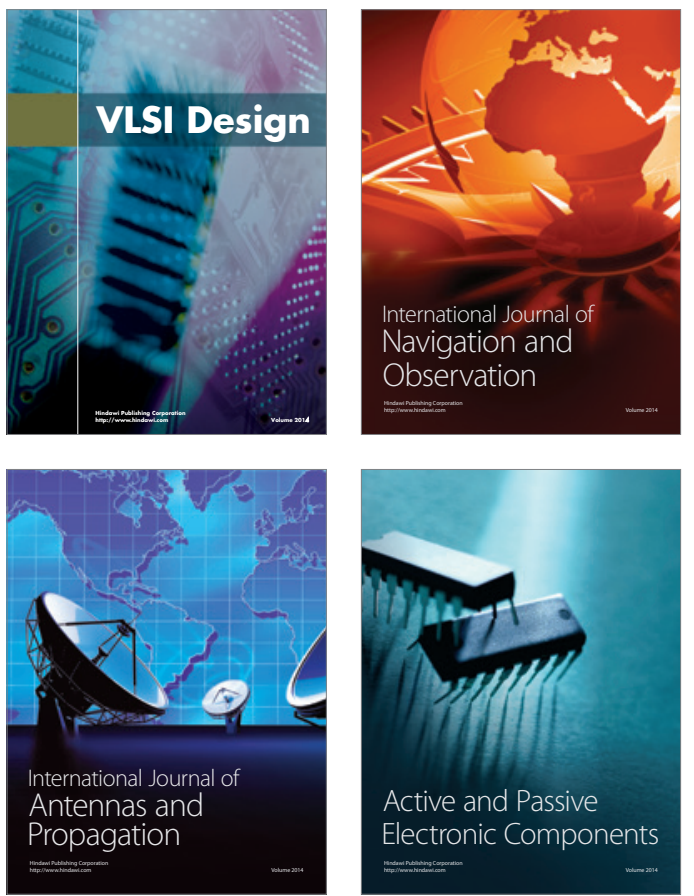
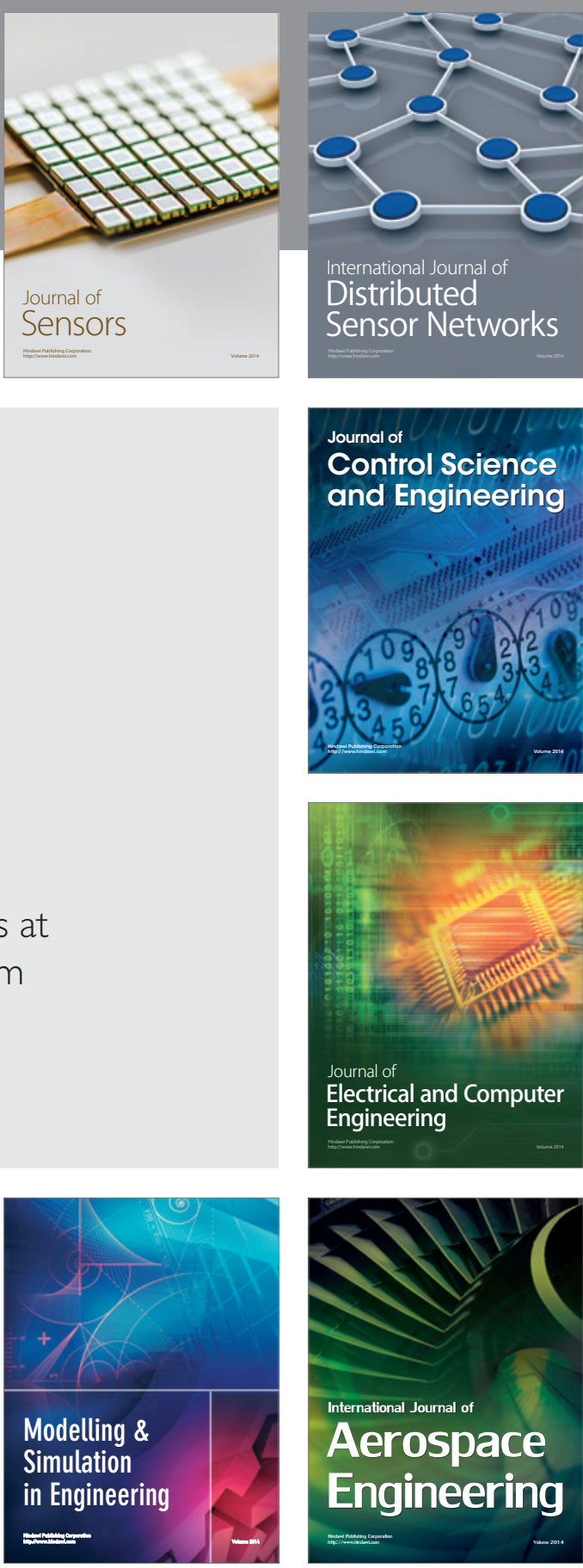

International Journal of

Distributed

Sensor Networks

Journal of

Control Science

and Engineering
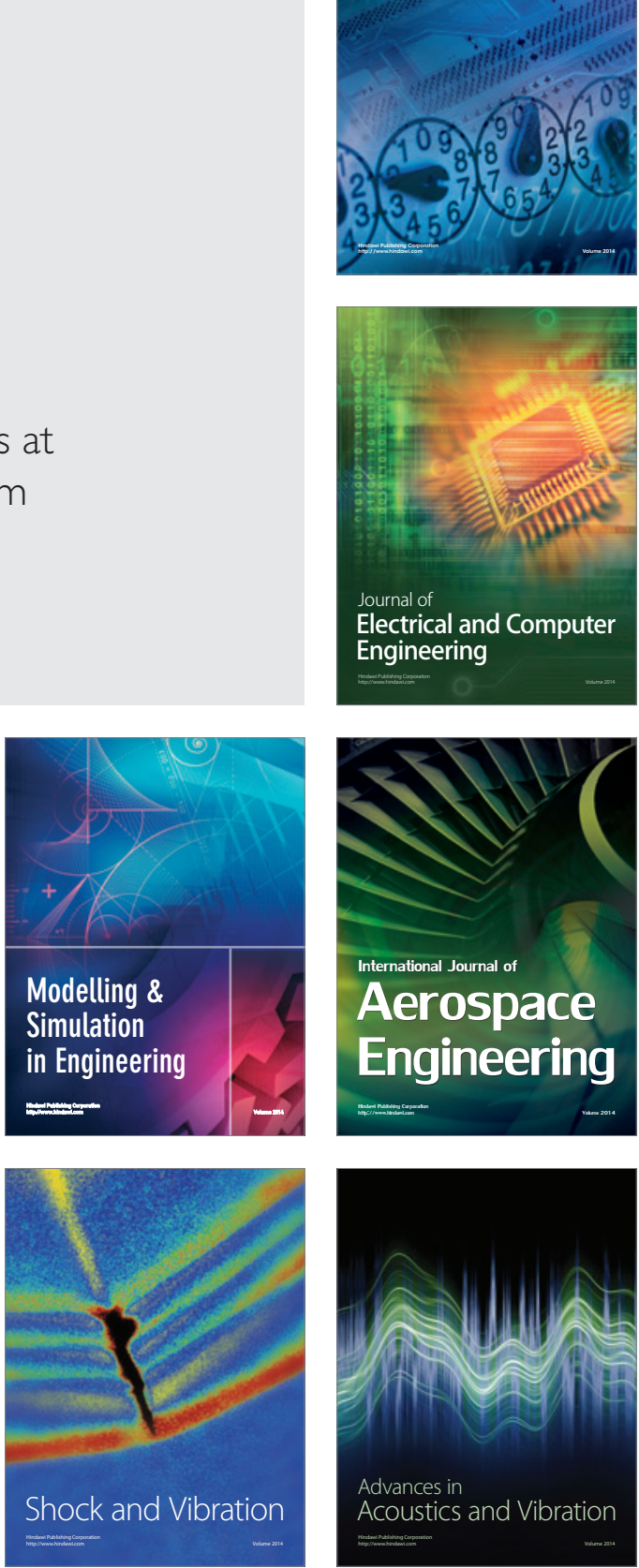